\title{
Pilot Study of Self-Measurement of Blood Glucose Using the Dextrostix-Eyetone System for Juvenile-Onset Diabetes
}

\author{
Y. Ikeda, N. Tajima, N. Minami, Y. Ide, J. Yokoyama, and M. Abe \\ The 3rd Department of Internal Medicine, The Jikei University School of Medicine, Tokyo, Japan
}

Summary. Self-measurement of blood glucose was performed by eight insulin-dependent juvenile-onset diabetics. The patients were well motivated and improved control of diabetes was obtained. The method would seem to be useful for juvenile-onset diabetics, especially of the unstable type and for pregnant diabetics.

Key words: Juvenile-onset diabetes, blood glucose, self-measurement, Dextrostix-Eyetone system, patient education.

The Dextrostix-Eyetone System is a simple and reliable method of blood glucose measurement [1]. This study was performed to evaluate the effect of selfmeasurement on control of diabetes. We started the trial with the view that better control of diabetes would be obtained by giving the responsibility to the patients.

\section{Materials and Methods}

Subjects comprised 8 insulin-treated juvenile-onset diabetics (male 5, female 3). Table 1 shows their details.

Blood was taken from earlobes or finger-tips by needle puncture. Blood glucose was checked using the Dextrostix-Eyetone System (D-E system) by patients themselves.

After the patients became used to operating the instruments, they started checking their fasting blood glucose (FBG) daily for the first three months and then three times weekly. Occasionally, post prandial blood glucose levels were also measured. Patients visited the Out-Patient Clinic every 2 weeks. Patients and their family, doctors and technicians also met once every three months for discussion.

Diabetic control was evaluated by the mean value of FBG and its standard deviation. $\mathrm{FBG} \pm \mathrm{SD}$ was calculated at 2 monthly intervals and compared with that of the previous year, which was chosen as a control. Changes of body weight and dosage of insulin were also recorded. The Eyetone instruments were provided by courtesy of Ames Company for 5 patients.

\section{Results}

\section{The Reliability of D-E System}

The accuracy of the D-E system has been reported $[1,2]$. We made a comparison between blood glucose Eyetone results and those obtained with the auto-

Table 1. Clinical profile of the patients

\begin{tabular}{lllllll}
\hline Patient & Age/Sex & $\begin{array}{l}\text { Duration } \\
\text { (years) }\end{array}$ & $\begin{array}{l}\text { Hight } \\
(\mathrm{cm})\end{array}$ & $\begin{array}{l}\text { Body weight } \\
(\mathrm{kg})\end{array}$ & $\begin{array}{l}\text { Insulin dose } \\
\text { (units/day) }\end{array}$ & Social status \\
\hline 1. & $18 / \mathrm{M}$ & 3 & 173 & 47 & Lente 32 & Student \\
2. & $24 / \mathrm{F}$ & 15 & 148 & 44 & Lente 56, Act 24 & College Graduate \\
3. & $20 / \mathrm{F}$ & 8 & 156 & 60 & Lente 44, Act 12 & College Graduate \\
4. & $46 / \mathrm{M}$ & 19 & 158 & 42 & Lente 20, Act 12 & Teacher \\
5. & $26 / \mathrm{M}$ & 12 & 167 & 59 & Lente 56, Rap 28 & Hoacher \\
6. & $27 / \mathrm{F}$ & 5 & 153 & 53 & Lente 16 & Office Worker \\
7. & $39 / \mathrm{M}$ & 11 & 163 & 48 & Lente 16 & Student \\
8. & $24 / \mathrm{M}$ & 11 & 165 & 46 & Lente 40 & \\
\hline
\end{tabular}


analyzer ferricyanide reduction method [3]. A positive correlation was found $(\mathrm{r}=0.96)$. The value measured by the D-E system was slightly higher when it exceeded $200 \mathrm{mg} / \mathrm{dl}$ [4].

A second check was also performed: two hours after a meal, blood was taken 3 times consecutively by a technician and blood glucose was measured by autoanalyzer. At the same time, patients took blood and measured glucose with the D-E system. The results are summarized in Table 2 . Although the difference between the two methods became slightly greater when the value exceeded $300 \mathrm{mg} / \mathrm{dl}$, the patients' own measurements showed little variation.

\section{Self-Measurement of Blood Glucose and Clinical Course of Diabetes}

Table 3 shows the mean value and standard deviation of FBG level by D-E system at 2 monthly intervals.

Table 2. The validity of measurement of blood glucose level by the patients using the D-E system and comparison with that by A-A method

\begin{tabular}{|c|c|c|c|c|c|}
\hline \multirow{2}{*}{ Patient } & \multicolumn{5}{|c|}{ Blood glucose level by D-E system and A-A method } \\
\hline & Method & $3 \mathrm{Mer}$ & rements & $(\mathrm{mg} / \mathrm{dl})$ & Average \\
\hline \multirow[t]{2}{*}{1.} & D-E & 350 & 350 & 330 & 343 \\
\hline & A-A & 308 & 317 & 323 & 316 \\
\hline \multirow[t]{2}{*}{2.} & D-E & 330 & 350 & 340 & 340 \\
\hline & A-A & 314 & 313 & 322 & 316 \\
\hline \multirow[t]{2}{*}{3.} & D-E & 270 & 280 & 280 & 277 \\
\hline & $A-A$ & 264 & 260 & 265 & 263 \\
\hline \multirow[t]{2}{*}{4.} & D-E & 240 & 210 & 210 & 220 \\
\hline & $A-A$ & 207 & 201 & 209 & 206 \\
\hline \multirow[t]{2}{*}{5.} & D-E & 220 & 220 & 205 & 215 \\
\hline & $A-A$ & 215 & 209 & 217 & 214 \\
\hline \multirow[t]{2}{*}{6.} & D-E & 170 & 170 & 150 & 163 \\
\hline & A-A & 146 & 158 & 154 & 153 \\
\hline \multirow[t]{2}{*}{7.} & D-E & 120 & 130 & 130 & 127 \\
\hline & $A-A$ & 129 & 131 & 133 & 131 \\
\hline \multirow[t]{2}{*}{8.} & D-E & 115 & 130 & 108 & 118 \\
\hline & $A-A$ & 100 & 99 & 100 & 100 \\
\hline
\end{tabular}

The FBG level after 6 months reached the desirable level in 4 of 8 cases. After one year, diabetes was well controlled with FBG of less than $120 \mathrm{mg} / \mathrm{dl}$ in 5 of 8 cases. Body weight did not change significantly except in Case 1, who gained $7 \mathrm{~kg}$ weight up to $54 \mathrm{~kg}$.

\section{Evaluation of Self-Measurement of Blood Glucose}

According to the data obtained we have evaluated this method and summarized as follows;

1) Patients were motivated to maintain their blood glucose within normal range by the frequent checking of blood glucose. Consequently, they became eager to regulate their daily life. This positive attitude was observed in all cases.

2) The method encouraged patients to become more involved in dietary control.

3) Since blood glucose and urine glucose level can be checked simultaneously, the relationship between the two became obvious.

4) As they checked blood glucose every day instead of once per fortnight, more information on diabetic control became available which facilitated proper insulin dosage. Adjustment of insulin dosage could be made with confidence.

5) Metabolic disorder could be normalized quickly.

\section{Discussion}

Among the various indices available, blood glucose, especially the fasting level, is said to be the most useful indicator of metabolic status even in juvenile onset diabetes. It should be checked more frequently and more accurately. At best in the diabetes clinic, FBG is measured only once each fortnight. Young diabetics, especially unstable cases, cannot be controlled well by this kind of management.

Self-measurement of blood glucose, using the DE system, gave unexpectedly good results. This might partly be due to the careful selection of the subjects,

Table 3. Changes of FBG level during the test period

\begin{tabular}{llllrrrr}
\hline & \multicolumn{2}{l}{ FBG $(\mathrm{mg} / \mathrm{dl})$} & & & & \\
Patient & \multicolumn{1}{l}{ pre } & 2 & 4 & 6 & 8 & 10 & 12 months \\
\hline 1. & $158 \pm 43$ & $205 \pm 37$ & $127 \pm 42$ & $120 \pm 36$ & $118 \pm 33$ & $113 \pm 23$ & $118 \pm 25$ \\
2. & $386 \pm 127$ & $330 \pm 96$ & $324 \pm 89$ & $311 \pm 54$ & $234 \pm 111$ & $177 \pm 127$ & $181 \pm 51$ \\
3. & $196 \pm 62$ & $145 \pm 45$ & $151 \pm 50$ & $155 \pm 48$ & $131 \pm 42$ & $106 \pm 33$ & $117 \pm 28$ \\
4. & $210 \pm 54$ & $190 \pm 86$ & $145 \pm 70$ & $114 \pm 49$ & $70 \pm 16$ & $118 \pm 28$ & $106 \pm 45$ \\
5. & $159 \pm 49$ & $154 \pm 18$ & $149 \pm 23$ & $153 \pm 24$ & $162 \pm 39$ & $143 \pm 22$ & $149 \pm 14$ \\
6. & $119 \pm 13$ & $135 \pm 37$ & $85 \pm 10$ & $95 \pm 9$ & $162 \pm 39$ & $120 \pm 24$ & $96 \pm 15$ \\
7. & $108 \pm 14$ & $115 \pm 13$ & $125 \pm 13$ & $103 \pm 23$ & $77 \pm 13$ & $87 \pm 20$ & $90 \pm 16$ \\
8. & $315 \pm 50$ & $214 \pm 65$ & $226 \pm 66$ & $201 \pm 59$ & $228 \pm 58$ & $280 \pm 52$ & - \\
\hline
\end{tabular}


choosing patients who were intelligent and skilful in using the instruments. The patients did not become anxious; in fact, the better the control of blood glucose, the happier the patients.

The method would seem to be useful for insulindependent juvenile-onset diabetics, especially of the unstable type, and during pregnancy.

Having finished this pilot study of one year, we feel that the development of a more simple and reliable instrument should be pursued, the cost should be lowered and that painless needle puncture should be developed.

\section{References}

1. Cohen, S. L., Legg, S., Lond, M. B.: A bedside method of blood glucose estimation. Lancet 1964 II, 883-884
2. Jarrett, R. J., Keen, H., Hardwick, C.: "Instant" blood sugar measurement using dextrostix and a reflectance meter. Diabetes 9, 724-726 (1970)

3. Hoffman, W. S.: A rapid photoelectric method for the determination of glucose in blood and urine. J. Biol. Chem. 120, 51-55 (1937)

4. Ide, Y., Motoyoshi, M., Tanese, T.: Dextrostix-Eyetone System for determination of blood glucose. Jpn. Med. J. 2681, 43-46 (1975)

Received: January 9, 1978,

and in revised form: March 10, 1978

Dr. Y. Ikeda

The 3rd Department of Internal Medicine

The Jikei University School of Medicine

3-25-8 Nishi-Shinbashi, Minato-ku

Tokyo 105

Japan 